\title{
Agile Approach in Training Future Primary School Teachers for Resolving Complex Pedagogical Situation
}

\author{
Olha A. Komara, Yuliia M. Chuchalina ${ }^{b}$, Alla N. Kramarenkoc, Tamara A. \\ Torchynska ${ }^{d}$, Iryna V. Shevchuk*e
}

$\begin{array}{ll}\text { Received } & : \text { 23 February } 2021 \\ \text { Revised } & : 28 \text { February } 2021 \\ \text { Accepted } & : \text { 26 March } 2021 \\ \text { DOI } & : 10.26822 / \text { iejee.2021.205 }\end{array}$

a.Olha A. Komar, Department of Professional Methodologies and Innovative Technologies in Primary School, Faculty of Primary Education, Pavlo Tychyna Uman State Pedagogical University, 2, Sadova St., Uman, 20300, Ukraine. ORCID: https://orcid.org/0000-0003-0289-2359

bYuliia M. Chuchalina, Department of Professional Methodologies and Innovative Technologies in Primary School, Faculty of Primary Education, Pavlo Tychyna Uman State Pedagogical University, 2, Sadova St., Uman, 20300, Ukraine.

ORCID: https://orcid.org/0000-0001-5350-8236

- Alla N. Kramarenko, Department of Primary Education, Faculty of Psychological and Pedagogical Education and Arts, Berdyansk State Pedagogical University, 4,Schmidta St, Berdiansk, 71118, Ukraine. ORCID: https://orcid.org/0000-0003-3922-4979

${ }^{d}$ Tamara A. Torchynska, Department of Professional Methodologies and Innovative Technologies in Primary School, Faculty of Primary Education Pavlo Tychyna Uman State Pedagogical University, 2, Sadova St., Uman, 20300, Ukraine. ORCID: https://orcid.org/0000-0001-9304-4026

${ }^{e}$ Correspondig author: Iryna V. Shevchuk, Department of Professional Methodologies and Innovative Technologies in Primary School, Faculty of Primary Education, Pavlo Tychyna Uman State Pedagogical

University, 2, Sadova St., Uman, 20300, Ukraine. E-mail: irynaa1975@gmail.com

ORCID: https://orcid.org/0000-0001-9507-6048

\begin{abstract}
The article presents the results of an experimental study of the impact of scrum methodology as a kind of Agile approach on building competence in resolving complex pedagogical situations in future primary school teachers. It is noted that the experiment was conducted in the first semester of the 2018-2019 academic year and covered fourth-year students majoring in 013 "Primary Education" at Pavlo Tychyna Uman State Pedagogical University and Berdiansk State Pedagogical University. The author reveals the peculiarities of adaptation of the scrum methodology to the traditional educational process, distribution of academic time into periods in accordance with iterative processes of educational assignments. The specifics of the scrum methodology, the role and relationship of teacher and students, the process and procedures of creating the final product - a portfolio of analysed and resolved complex pedagogical situations, as well as a compendium of relevant case studies and teaching materials. Procedures for the formation of experimental and control groups and ensuring the statistical reliability of the results are covered. Diagnostic methods for determining the resulting variables are described, namely: the ability of students to resolve complex pedagogical situations, the quality of learning and motivation of students to learn. It is experimentally proven that the scrum methodology promotes the development of students' ability to resolve complex pedagogical situations, increase the quality of education and motivation to learn in training future primary school teachers.
\end{abstract}

\section{Keywords:}

Primary School Teacher, Agile Approach, Scrum Methodology, Complex Pedagogical Situations, Quality of Education, Motivation to Learn

\section{Introduction}

In order to perform its essential functions, higher education I must constantly change and adapt to modern conditions. This is the concept of VUCA world (U.S. Army Heritage and Education Center, 2019). Agile approach was proposed in response to the challenges of VUCA world first in military practice and later in other areas, such as programming, logistics, manufacturing, etc. Subsequently, the process 
of implementing the Agile concept in higher educational institutions regarding the training of specialists in information systems and technologies, programming, computer science, engineering, etc. began (Krehbiel et al., 2017). It is mostly a scrum methodology (Schwaber \& Sutherland, 2020), which is one of the main components of the Agile concept. Scrum methodology involves the use of self-organizing teams to create a specific intellectual product, dividing the process into separate sequential iterations and applying the Agile Principles.

The study of relevant research and world experience shows that there is still a lack of research in the field of high school pedagogy that would reveal the specifics of the application of the Agile concept in training of primary school teachers. At the same time, our analysis shows that the scrum methodology, with its essential features, can be used in training of future primary school teachers to resolve complex pedagogical situations.

This confirms the topicality of our research and gives grounds to determine the aim of the study, which is to experimentally test and justify the use of the scrum methodology in training future primary school teachers for resolving complex pedagogical situations.

\section{Literature review}

Reviewing the relevant scientific literature, we must first pay attention to the origins of the Agile approach and its gradual adaptation to the resolution of pedagogical problems, in particular, the application in the training of primary school teachers.

The Agile approach is the result of finding ways and means to solve complex problems in connection with the VUCA world's challenges, which, in particular, is characterized by the concept of ambiguity, that is instability, uncertainty, complexity. The VUCA concept assumes that the modern world offers ambiguity situations in which events and information can be given different interpretations, as ambiguity does not allow to find only one "correct" interpretation and confidently offer a single solution (Stewart et al., 2015). A key feature in dealing with ambiguity situations is Agility, which involves the ability of a person or group to be flexible, innovative and learn quickly from mistakes (Scott, 2020).

Despite the fact that the VUCA concept was intended for military action in cases where the combat situation is constantly changing, this idea has become widespread in other areas of professional activity, including pedagogical practice. Here we should refer to the publication of a group of teachers who presented the results of a two-year experiment of implementing the Agile Way of Work method. These materials show that Agile's adaptation to higher education has yielded positive results: attracting students to cooperate, encouraging them to take responsibility for their learning, improving the level and quality of cooperation and obtaining better learning outcomes. In addition, the authors argue that it is effective to use the Scrum methodology, which involves the creation of self-organizing teams with different skills to develop work products in small sequential iterations (Krehbiel et al., 2017).

Riedler and Eryaman (2016) cover methodological aspects of teacher training for professional activity under the conditions of complexity, diversity and ambiguity. The authors explore the possibility of applying a phronetic approach to teacher training, that is teaching them to quickly make the right decisions, perform correct actions, the ability to distinguish good from bad in particular pedagogical situations.

Sipman et al. (2019) developed this topic. Through focus group discussions with teachers and school principals, scholars view intuition as a crucial competence for teachers' pedagogical tact. We consider their conclusion about the need to develop intuition important in resolving complex pedagogical situations. This gives grounds to use this idea in experimental research.

Another work related to the research problem is the article by Sharp and Lang (2018), which summarizes six cases of application of the Agile concept in building student competencies in the field of information systems. The authors classify the Agile-related literature in teaching by two axes of pedagogy: 1) teaching students Agile technology for its further application in professional activities; 2) the use of Agile as a pedagogical method.

In their article, Hulshult and Krehbiel (2019) describe the experience of implementing Agile practices integrated into the online learning of graduate students majoring in Computer Information Technology at the University of Miami. Their experience of using Agile practices such as team charters, daily stand-ups, Kanban boards, story cards, MosCoW, timeboxing, showcases and retrospectives, etc. is valuable. Similar problems are described in the article by Lang (2017).

The publication by Magnuson and Cosgrove (2019) summarizes the experience of using Agile practices in teaching students of Leysin American School. In particular, the researcher describes ten practices that are successfully used in schools.

López-Alcarria et al. (2019) provide a systemic overview of the use of the Agile approach in building 
competencies of sustainable development in lifelong learning. The authors argue that Agile learning creates favourable learning conditions, while improving outcomes and increasing the level of motivation of both teachers and students.

Udas et al. (2018) consider the problems of applying the Agile approach in the evaluation and use of demonstration technologies for innovation in the higher education system. Yakovyshyna (2018) provides theoretical substantiation of the Agile approach in the modernization of higher education. In their article, Ivetić and Ilić (2020) discuss possibilities and conditions of Agile implementation in higher educational institutions, values, principles and different practices of Agile, which is important for the development of experimental research methodology.

Among the few publications on the problem of the Scrum approach in training of primary school teachers, we should mention the article by Stakhova (2020), who explores the possibilities of the Scrum approach in making future teachers ready for environmental activities in primary school.

In her work, Minhalova (2018) covers the principles of agile management of Scrum projects in the research of students. Anufrieva (2020) considers the possibility of using Agile and Scrum in teaching macroeconomic subjects for masters in Entrepreneurship, Trade and Exchange Activities.

Pannier's (2020) publication addresses the effectiveness of Agile in collaboration with primary school teachers when developing a game platform. The analysed publications reveal the theoretical and practical aspects of the Agile approach in the pedagogical practice of higher educational institutions, mostly in training specialists in computer science, information systems, engineering, etc. At the same time, there is a lack of research that reveals the specifics of the application of the Agile concept in training primary school teachers. The authors emphasize that one of the main Agile-related techniques is the use of the Scrum methodology, which involves the use of selforganizing teams with different skills to create work products in small sequential iterations. This confirms the topicality of our research and gives grounds to focus it on the use of the Scrum methodology in training of future primary school teachers to resolve complex pedagogical situations.

\section{Methods}

The study used the scrum methodology - dividing the experimental group of students into teams, each receiving assignments and instructions for analysis and resolution of complex pedagogical situations, as well as receiving explanations about the Scrum methodology and printed instructions for participation in the experiment.

To prove or disprove the effectiveness of the Scrum methodology, weused an experimental method having formed two groups of students - experimental and control. This procedure was performed in two stages using a sampling method. At the first stage, a sample of 68 people was formed by random sampling at the level of confidence probability $p=95 \%$, (confidence interval $\Delta= \pm .05$ ) of the general population (a total of 82 fourth-year students majoring in 013 "Primary Education" at Pavlo Tychyna Uman State Pedagogical University and Berdiansk State Pedagogical University). In the second stage, 35 students were selected from the sample in the experimental group and 33 students in the control group. The groups were equalized through the random division of students into experimental and control groups according to the following criteria: age, gender, level of ability to resolve complex pedagogical situations, quality of learning and motivation to learn.

The study used a model of the experiment "Beforeafter with the control group". The experimental group studied according to the Scrum methodology, the control group - according to the traditional one. Three methods were used to diagnose the resulting variables (the ability to resolve complex pedagogical situations, the quality of learning and motivation to learn). The first (expert assessment method) was aimed at determining the level of students' ability to resolve complex pedagogical situations. The diagnostic procedure provided that each student was given texts describing pedagogical situations (a total of four situations). According to the instructions, each participant had to suggest 3-5 options for resolving the situation and provide a justification for the most acceptable choice. The completed assignments were subject to analysis and evaluation by an expert (teacher) according to the criteria at four levels: creative, partially search, reproductive and unconscious (spontaneous).

The level of students' ability to resolve complex pedagogical situations was determined through the following criteria. The creative level was determined by the ability to: independently model an original, non-typical way of resolving a situation; carry out the deep pedagogical analysis of a situation; justify the compliance of the chosen option with the conditions of the situation; predict the pedagogical consequences of the proposed solution. The partially search level included the following features: adapt the known methods of addressing the changed conditions of the proposed situation; analyse the content and conditions of the situation; substantiate own choice of the resolution of a pedagogical situation; predict the possible consequences of the 


\section{iejee}

proposed solution. The reproductive level met the following criteria: copying known, traditional ways of resolving the situation; artificial transfer of previously known ways of resolving the situation without taking into account its conditions; too general substantiation of one's own resolution to the situation, as it had little to do with the situation; insufficiently clear definition of the possible consequences of the proposed solution. The unconscious (spontaneous) level was determined by the following features: the erroneous resolutions of pedagogical situations; inability to justify one's choice; the conditions of origin and development of the situation are not taken into account; the consequences of one's proposal to resolve the situation are not foreseen (Kaplinskyi, 2015).

The quality of education was determined by the ECTS system (European Credit Transfer and Accumulation System): a high level was correlated with A grade (90-100 points), a sufficient level was determined by $B$ and $C$ grades (75-89 points), the average level corresponded to D and $E$ grades (60-74 points), low FX and F grades (1-35 points).

Levels of student motivation to learn were studied using a survey method, where the answers to relevant questions were arranged according to the Likert scale, which gave grounds to divide students by levels: high, medium, below average, low.

The information obtained during the experiment was analysed using the methods of mathematical statistics: Pearson's chi-square test, Chuprov's correlation coefficient, calculation of confidence probability and the level of statistical significance. Expert assessment and survey data were presented in tabular and graphical form.

\section{Results}

At the pre-experiment stage, a zero data slice was made in the experimental and control groups, which consisted in establishing their homogeneity in terms of ability to resolve complex pedagogical situations, quality of education and motivation to study in higher educational institution. Table 1 presents the results of diagnosing the levels of students' ability to resolve complex pedagogical situations.

Comparison of experimental and control groups by factor characteristics (Table 1) gives grounds to speak about their practical similarity (critical value $\chi^{2}$ at significance level $p<.05$ is 7.815 , significance level $p>.05$ ). It is worth noting that in both groups there was a lack of students with a creative level of ability to resolve complex pedagogical situations, while the largest share was represented by students of reproductive level, namely: 17 people $(48 \%)$ in the experimental group and 15 people (45\%) in the control group.

The zero data slice was made for the quality of education of students in both groups (Table 2).

\section{Table 1.}

Levels of ability to resolve complex pedagogical situations (before the experiment)

\begin{tabular}{lrrrr}
\hline Levels & \multicolumn{2}{r}{ Experimental group } & \multicolumn{2}{c}{ Control group } \\
\cline { 2 - 5 } & People & $\%$ & People & $\%$ \\
\hline Creative & 0 & 0 & 0 & 0 \\
Partially search & 8 & 23.0 & 10 & 30.5 \\
Reproductive & 17 & 48.0 & 15 & 45.5 \\
Unconscious & 10 & 29.0 & 8 & 24.0 \\
(spontaneous) & & & & \\
Total: & 35 & 100 & 33 & 100 \\
\hline
\end{tabular}

Table 2.

Indicators of the quality of student learning (before the experiment)

\begin{tabular}{lrrrr}
\hline Learning quality & \multicolumn{2}{c}{ Experimental group } & \multicolumn{2}{c}{ Control group } \\
\cline { 2 - 5 } levels & People & $\%$ & People & $\%$ \\
\hline High & 2 & 6.0 & 3 & 9.5 \\
Sufficient & 12 & 34.0 & 14 & 42.0 \\
Medium & 15 & 43.0 & 13 & 39.0 \\
Low & 6 & 17.0 & 3 & 9.5 \\
Total: & 35 & 100 & 33 & 100 \\
\hline
\end{tabular}

Calculations of the relevant statistical indicators give grounds to state the absence of differences between the experimental and control groups on the indicators of learning quality ( $\chi^{2}=7.815$ at the level of confidence value $p=0.996: \chi^{2} \mathrm{emp}=0.63<\chi^{2} \mathrm{cr0} 0.05=7.815$ ). Another important result and indicator, which probably could affect the outcome of the experiment, was the students's motivation to learn. Table 3 contains the relevant data obtained by interviewing students before the experiment.

Table 3.

Students' motivation to learn (before the experiment)

\begin{tabular}{lrrrr}
\hline Level of motivation & \multicolumn{2}{c}{ Experimental group } & \multicolumn{2}{c}{ Control group } \\
\cline { 2 - 5 } to learn & People & $\%$ & People & $\%$ \\
\hline High & 2 & 6.0 & 3 & 9.5 \\
Sufficient & 9 & 26.0 & 11 & 33.0 \\
Below medium & 14 & 40.0 & 12 & 36.5 \\
Low & 10 & 28.0 & 7 & 21.0 \\
Total: & 35 & 100 & 33 & 100 \\
\hline
\end{tabular}

Calculation of the statistical criterion according to Table 3 indicates no differences between groups $\left(x 2_{\text {emp }}=0.462<\chi_{\text {cro.05 }}=7.815\right.$ at the confidence level $p$ $=0.928)$.

Thus, the obtained data and relevant statistical 
calculations show that the selected groups of students are almost identical in terms of levels of the ability to resolve complex pedagogical situations, quality of learning and motivation to learn, which is important for testing the effectiveness of the Scrum methodology.

The effectiveness of the experimental methodology was tested during the first semester of the 2018-2019 academic year and concerned the study by students of a special practical course Methods of Resolving Complex Pedagogical Situations in the fourth year for students majoring in 013: Primary Education. The students of the experimental group were informed about the survey, and received explanations about the Scrum methodology, as well as printed instructions for participation in the experiment. The experimental group was divided into five self-managed teams of seven people. The academic semester was divided into eight two-week periods (sprints) to perform iterative processes, resulting in a final product - a portfolio of analysed and resolved complex pedagogical situations, as well as a compendium of relevant cases and teaching materials.

The teacher-student relationships were defined by such roles as product owner, scrum team, scrum master. The teacher performed the role of the product owner, who offered the assignment to the groups according to the backlog (order). The assignment consisted of a description of complex pedagogical situations, as well as the structure of their analysis and resolution. The product owner acted as coach, monitored the process, set priorities, and received interim reports after each sprint.

The students selected in each group performed the role of Scrum masters. According to their functions, scrum masters supported team spirit, facilitated the planning and execution, were the link between the group and the teacher, kept a portfolio of meetings, stand-ups and other materials of the group.

The role of Scrum teams was determined by the assignment according to which they analysed in detail the pedagogical situations offered to them, developed scenarios for their resolution, substantiated and provided recommendations to the participants of the situation. In addition, all team members participated in stand-up meetings (stand-ups) lasting up to 10 minutes twice a week, where they discussed current issues of the group according to the scheme: "What did you manage to do?", "What difficulties arose?", "What is it planned to do?"

The activities and relationships of the participants in the Scrum process were governed by the Agile Principles, which provided a high level of group and individual activity of students, their commitment, independence and responsibility for the quality of educational activities.

The training course was divided into eight sprints lasting two weeks each. The first four sprints dealt with the development of four projects for resolving difficult pedagogical situations. The fifth to eighth sprints consisted in developing case studies that contained complex pedagogical situations.

In the first lesson, the teacher delivered an introductory speech, talking about the relevance, aim and content of the course, the features of the Scrum methodology. Organizational issues were resolved: division into teams, election of Scrum masters, etc. In addition, each team was provided with a case that contained a brief description of a complex pedagogical situation, as well as assignments and instructions for their completion.

At the beginning of the next sprint, each group had a general discussion of the purpose and stages of work. Students independently selected short assignments, distributed them among themselves, set completion dates, as well as determined the dates of weekly stand-ups.

The sprint was followed by a retrospective team meeting, where students assessed the contribution of each to the overall result, reflected on how individual contributions contributed to the overall goal, how the team worked as a whole, how team members interacted, what methods and tools were involved.

A general group review meeting was also held at the end of the sprint to summarize and discuss each team's reports and evaluate each team's contribution to the overall product, to identify best practices, and to share them with other teams. Working in Scrum teams, the students of the experimental group analysed and provided justifications for resolving 20 complex situations and prepared a compendium of cases with complex pedagogical situations, as well as a description of their processing method.

The impact of the experimental factor on the development of the ability to resolve complex pedagogical situations was measured at the end of the experiment. Table 4 presents measurement results.

Comparison of experimental and control groups by factor characteristics did not reveal statistical differences ( $x 2$ is 3.109, the critical value of $\chi^{2}$ at a significance level of $p<.05$ is 7.815). However, a more detailed analysis showed that significant changes occurred in a subgroup of students with a creative level of ability to resolve complex pedagogical situations: their share in the experimental group was almost twice as high as in the control group (17\% 


\section{iejee}

vs. 9\%). There was also a significant increase in the number of students with a partially search level: $26 \%$ in the experimental group as opposed to $16 \%$ in the control group.

Table 4.

Levels of ability to resolve complex pedagogical situations (after the experiment)

\begin{tabular}{lrrrr}
\hline Levels & \multicolumn{3}{c}{ Experimental group } & \multicolumn{2}{c}{ Control group } \\
\cline { 2 - 5 } & People & $\%$ & People & $\%$ \\
\hline Creative & 6 & 17.0 & 3 & 9.0 \\
Partially search & 17 & 49.0 & 15 & 46.0 \\
Reproductive & 12 & 34.0 & 13 & 39.0 \\
Unconscious & 0 & 0 & 2 & 6.0 \\
(spontaneous) & & & & \\
Total: & 35 & 100 & 33 & 100 \\
\hline
\end{tabular}

Another distinctive trend of the obtained data was that all students of the experimental group with an unconscious (spontaneous) level of the relevant ability (10 people or $29 \%$ ) raised it to reproductive (4 people) and partially search (6 people) levels. At the same time, the number of students of the same level decreased by 6 people (18\%) in the control group. Figure 1 visually reflects the revealed tendencies.

The identified differences show certain advantages of the Scrum methodology in terms of developing students' ability to resolve complex pedagogical situations. One of the objectives of the study was to test the hypothesis about the impact of the Scrum methodology on the quality of student learning. Table 5 presents empirical data of the final slice of the quality of education of students of the experimental and control groups.

According to Table 5, no statistical differences were found between the experimental and control groups ( $x 2$ is 3.550 , the critical value of $\chi 2$ at the significance level $p<.05$ is 7.815), however, there was an increase in the quality of student learning in the experimental group. Compared to the indicators of zero data slice, the number of students with a high and sufficient level increased by 11 people and amounted to 25 (71.0\%), while similar changes in the control group were not so noticeable. Figure 2 presents the given dynamics. On the basis of the recorded changes, it is possible to draw a reasonable conclusion about the positive impact of experimental methods on the quality of student learning in the experimental group.

According to a survey conducted after the experiment, there was a significant increase in student motivation to learn under the influence of experimental technique. The number of students with a high level of motivation increased by 8 people, and with a medium - by 6 people compared to the situation before the experiment. At the same time, the corresponding indicators were not significant in the control group (Table 6).

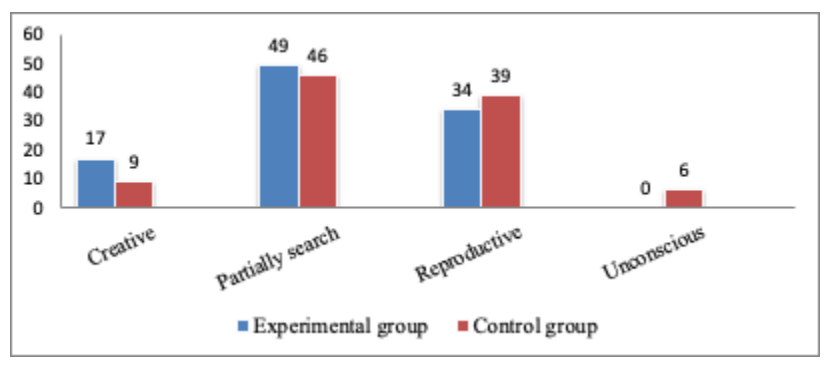

Figure 1.

Comparison of the ability to resolve complex pedagogical situations of students of the experimental and control groups (after the experiment, in \%)

Table 5 .

Indicators of student learning quality (after the experiment)

\begin{tabular}{lrrrr}
\hline Learning quality & \multicolumn{2}{c}{ Experimental group } & \multicolumn{2}{c}{ Control group } \\
\cline { 2 - 5 } & People & $\%$ & People & $\%$ \\
\hline High & 5 & 14.0 & 3 & 9.0 \\
Sufficient & 20 & 57.0 & 15 & 46.0 \\
Medium & 10 & 29.0 & 13 & 39.0 \\
Low & 0 & 0 & 2 & 6.0 \\
Total: & 35 & 100 & 33 & 100 \\
\hline
\end{tabular}

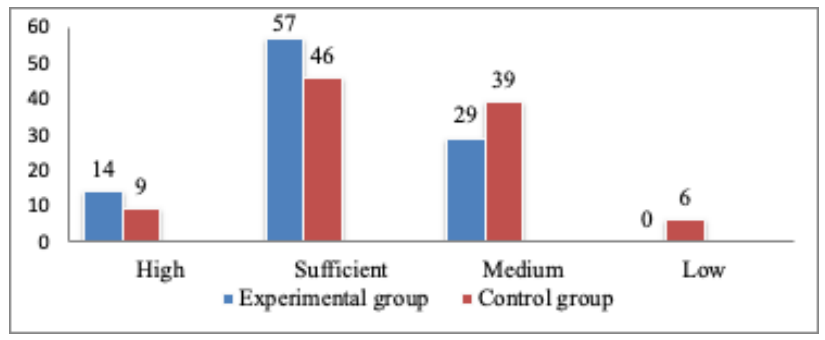

Figure 2.

Comparison of the quality of education of students of the experimental and control groups (after the experiment, in \%)

Table 6.

Students' motivation to learn (after the experiment)

\begin{tabular}{lrrrr}
\hline $\begin{array}{l}\text { Levels of motivation } \\
\text { according to the } \\
\text { survey }\end{array}$ & \multicolumn{2}{c}{ Experimental group } & \multicolumn{2}{c}{ Control group } \\
\cline { 2 - 5 } & People & $\%$ & People & $\%$ \\
\hline High & 10 & 29.0 & 4 & 12.0 \\
Medium & 15 & 43.0 & 12 & 36.0 \\
Lower than me- & 5 & 14.0 & 10 & 30.0 \\
dium & 5 & 14.0 & 7 & 22.0 \\
Low & 35 & 100 & 33 & 100 \\
Total: & & & & \\
\hline
\end{tabular}

The criterion $\chi 2$, calculated according to Table 6 , is 
8.499. The critical value of $\chi 2$ at the significance level $p=.05$ is 7.815. The relationship between factor and resultant characteristics is statistically significant at a significance level of $p<.05$. These data and the corresponding statistical calculations give reason to believe that learning with the use of the Scrum methodology has a positive effect on student motivation. Figure 3 graphically presents changes in student motivation.

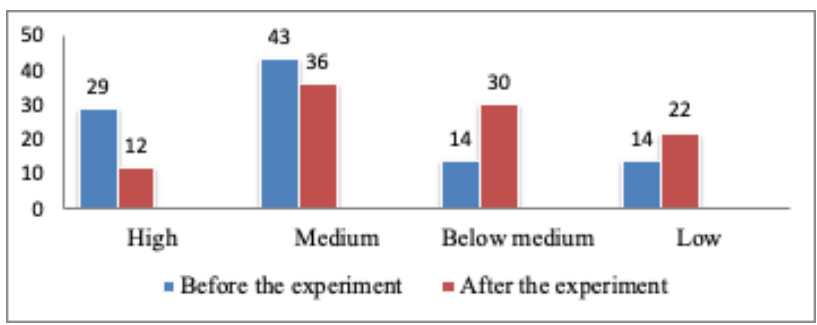

\section{Figure 3.}

Changes in motivation to learn in students of the experimental and control groups (after the experiment, in \%)

Further analysis of the obtained results was aimed at finding the mechanisms of influence of factors on the resulting variables, in particular, using the correlation method. Table 7 was prepared based on the results of expert assessment of the levels of ability to solve complex pedagogical problems and the results of the survey on the students' motivation to learn after the experiment.

\section{Table 7.}

Relationship between students' motivation and ability to resolve difficult pedagogical situations (after the experiment)

\begin{tabular}{|c|c|c|c|c|c|}
\hline \multirow[b]{2}{*}{$\begin{array}{l}\text { Levels of moti- } \\
\text { vation based on } \\
\text { survey results }\end{array}$} & \multicolumn{4}{|c|}{$\begin{array}{r}\text { Ability to resolve complex } \\
\text { pedagogical situations }\end{array}$} & \multirow[b]{2}{*}{ Total } \\
\hline & 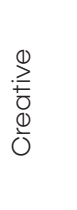 & 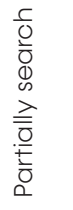 & $\begin{array}{l}\stackrel{0}{2} \\
\stackrel{2}{0} \\
\frac{2}{0} \\
\frac{0}{0} \\
\frac{0}{0} \\
\alpha\end{array}$ & 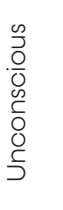 & \\
\hline High & 5 & 5 & 0 & 0 & 10 \\
\hline Medium & 1 & 9 & 5 & 0 & 15 \\
\hline Below medium & 0 & 3 & 1 & 1 & 5 \\
\hline Low & 0 & 0 & 4 & 1 & 5 \\
\hline Total: & 6 & 17 & 10 & 2 & 35 \\
\hline
\end{tabular}

Source: developed by the author

Calculated according to Table 7, Chuprov's correlation coefficient showed a fairly close correlation between factor (motivation) and the resultant (ability to resolve complex pedagogical situations) variables $(C=0.485$ at a significance level of $p<.01$ ). This gives grounds to claim that motivation to study significantly affects the development of students' ability to resolve complex pedagogical situations. On the other hand, we should note that in this case the main factor of influence is the Scrum methodology, which creates a situation of success, when achieving positive results in solving complex problems increases the level of motivation.

Thus, the results of experimental study proved the effectiveness of the Scrum methodology in building students' ability to resolve complex pedagogical situations and achieve better learning outcomes.

\section{Discussion}

The analysis of the obtained data showed that the students of the experimental group achieved significant learning outcomes in the ability to resolve complex pedagogical situations, distinguish different types of pedagogical situations according to their complexity, perform their step-by-step analysis, find causes, generate ideas for solving and eliminating causes. There was also a significant increase in the quality of learning and motivation of students in the experimental group. The correlation analysis helped to find that motivation to learn significantly affects the development of students' ability to resolve complex pedagogical situations.

The achieved results were obtained due to the ability to work in a Scrum team, combining with individual work, to use such tools of the scrum methodology as product backlog, distribution of roles and tasks, sprint planning, daily stand ups, iterative review, retrospective meetings, generation of ideas. The level of independence and responsibility of the students of the experimental group significantly increased, which ultimately affected the motivation of students and the results of the quality of learning.

At the same time, we should note that the students were confused in the first two weeks of the semester, because they got used to traditional learning, when teacher controls all issues of the educational process. The same situation was recorded in the study of Jurado-Navas and Munoz-Luna (2017) at the University of Malaga (Spain), although in general they confirmed the high efficiency of the Scrum methodology in training English teachers. Other studies raised similar problems, for example Vogelzang et al. (2020b) also note that the students who participated in the experiment were not familiar with the Scrum methodology, so they needed time to adapt to the procedures, roles, and conditions.

It is worth noting that there is a certain concern and frustration of teachers that not all students show activity, responsibility and desire to work together (Vogelzang et al., 2020a, p. 237). We concluded in the course of the research that teachers need to be trained on their role as coaches in the scrum learning process (Müller-Amthor et al., 2020). 


\section{iejee}

The solution to this problem in our study was realized by individually assessing the contribution of each student to each increment and the overall product. We found in the course of our study that the degree of team cohesion depended on the frequency of their weekly meetings: those teams that met 2-3 times a week worked more successfully than those that met once a week (Rush \& Connolly, 2020, p. 206).

In the next two weeks of our experiment, there was a gradual adaptation of students to independent learning, they addressed the teacher only in case of solving particularly difficult educational problems or team relations. Somestudents expressed dissatisfaction and desire to return to traditional education. In her study, Linden (2018) observed similar problems, who recorded a lack of motivation of disinterested students and a positive impact on their learning outcomes. Such considerations encourage more attention to study of the impact on the effectiveness of the scrum feedback methodology and teacher-student relationships in further research (Švejdarova, 2019). We should also pay attention to the students' proposals of involving them both in planning course design and product backlog for teams (Norberg et al., 2017).

Our research also encourages the solution of problems related to the Scrum methodology implementation in the educational process with strict planning of hours by type of classes and a significant reduction in classroom-based learning, etc. (Masood et al., 2018).

\section{Conclusion}

The experimental study gave us the results, which testify to the effectiveness of the Scrum methodology in training future primary school teachers to resolve complex pedagogical situations. During the experiment, students developed competencies to distinguish different types of pedagogical situations by their level of complexity, to carry out their stepby-step analysis, to find the causes of pedagogical situations, to generate ideas for their solution and elimination of causes. Besides, students gained skills and abilities to work in a Scrum team in combination with individual work, use tools such as role distribution, sprint, stand-up, brainstorming, increased the level of independence and responsibility. The results of the study convincingly prove that the quality of students' learning in the experimental group is significantly higher than in the control group. As a result of the diagnosis, we also found a significantly higher level of motivation to learn in the students of the experimental group in comparison with the control group. The answers to the open-ended questions of the final questionnaire testified to the mostly positive and enthusiastic responses to the scrum method. primary school teachers in higher education institutions, in the system of postgraduate pedagogical education, in the creation of textbooks for students majoring in 013: Primary Education. Further research on this problem is expected to explore the possibilities of applying the Agile approach in the development of such educational products as game techniques, scenarios for creative lessons, the development of individual educational learning trajectory of a child.

\section{References}

Anufrieva, O. (2020). The usage of Eduscrum in the educational process in institutions of higher education. EasyChair, 4414. https://easychair. org/publications/preprint/5xxp

Hulshult, A. R., \& Krehbiel, T. C. (2019). Using eight agile practices in an online course to improve student learning and team project quality. Journal of Higher Education Theory and Practice, 19(3), 5567.

Ivetić, P., \& Ilić, J. (2020). Reinventing universities: Agile project management in higher education. European Project Management Journal, 10, 6468.

Jurado-Navas, A., \& Munoz-Luna, R. (2017). Scrum methodology in higher education: Innovation in teaching, learning and assessment. International Journal of Higher Education, 6(6), 1-18.

Kaplinskyi, V. V. (2015). 100 difficult situations in class and out of class: looking for a solution: a textbook for teachers. TOV "Nilan-LTD".

Krehbiel, T. C., Salzarulo, P. A., Cosmah, M. L., Forrena, J., Gannod, G., Havelka, D. ... Merhout, J. (2017). Agile Manifesto for teaching and learning. The Journal of Effective Teaching, 17(2), 90-111.

Lang, G. (2017). Agile learning: Sprinting through the semester. Information Systems Education Journal, 15(3), 14-21.

Linden, T. (2018). Scrum-Based learning environment: Fostering self-regulated learning. Journal of Information Systems Education, 29(2), 65-74.

López-Alcarria, A., Olivares-Vicente, A., \& Poza-Vilches, F. (2019). A systematic review of the use of agile methodologies in education to foster sustainability competencies. Sustainability, 11, 2915. 
Magnuson, P., \& Cosgrove, N. (2019). Pulling agile into education. Spotlight. https:// resources.finalsite.net/images/v1571421333/ lasch/x6zkzvqfmlopo7rxnljy/spotlight_ Magazine_2019_DIGITAL.pdf.

Masood, Z., Hoda, R., \& Blincoe, K. (2018). Adapting agile practices in university contexts. The Journal of Systems and Software, 144, 501-510.

Minhalova, Yu. I (2018). Principles of the use of Flexible Management Scrum Projects in scientific and research work of students. Innovative Pedagogy, 7(2), 79-82.

Müller-Amthor, M., Hagel, G., Gensheimer, M., \& Huber, F. (2020). Scrum higher education - The Scrum master supports as solution-focused coach. IEEE Global Engineering Education Conference EDUCON (pp. 948-952). Porto, Portugal.

Norberg, A., Stockel, B., \& Antti, M.-L. (2017). Time shifting and agile time boxes in course design. International Review of Research in Open and Distributed Learning, 18(6), 88-103. https://doi. org/10.19173/irrodl.v18i6.3182

Pannier, C. (2020). Work methods for the 21st century. http://colinepannier.com/3-things-i-learnedagile-primary-school-teachers/

Riedler, M. \& Eryaman, M. Y. (2016). Complexity, diversity and ambiguity in teaching and teacher education: Practical wisdom. International Journal of Progressive Education, 12(3), 172-186.

Rush, D. E. \& Connolly, A. J. (2020). An agile framework for teaching with Scrum in the IT project management classroom. Journal of Information Systems Education, 31(3), 196-207.

Schwaber, K., \& Sutherland, J. (2020). The Scrum guide. The definitive guide to Scrum: The rules of the game. Scrum. https://www.scrumguides.org/ docs/scrumguide/v2020/2020-Scrum-GuideUS.pdf

Scott, W. B. (2020). How VUCA teaches agility. Insigniam. https://insigniam.com/blog/howvuca-teaches-agility/

Sharp, J. H., \& Lang, G. (2018). Agile in teaching and learning: Conceptual framework and research agenda. Journal of Information Systems Education, 29(2), 45-51.

Sipman, G., Tholke, J., Martens, R., \& McKenney, S. (2019). The role of intuition in pedagogical tact: Educator views. British Educational Research Journal, 45(6), 1186-1202.
Stakhova, I. A. (2020). The possibilities of using Scrum approach in the process of forming the preparation of environmental protection of future teachers in primary school. Innovative Pedagogy, 20(3), 68-74.

Stewart, B., Khare, A., \& Schatz, R. (2015). Volatility, uncertainty, complexity and ambiguity in higher education. In O. Mask, A. Khare, A. Krämer, T. Burgartz, (Eds.), Managing in a VUCA world (pp. 241-250). Springer International Publishing.

Švejdarova, E. (2019, July 1-3). Power of feedback - Agile project learning. Proceedings of EDULEARN19. Conference. Palma, Mallorca, Spain.

U.S. Army Heritage and Education Center. (2019). Who first originated the term VUCA (Volatility, Uncertainty, Complexity and Ambiguity)? https://usawc.libanswers.com/faq/84869

Udas, K., Brosnan, S., \& Wade, B. (2018). Let's talk pedagogy: An agile approach to testing and demonstrating. Education Technology Solutions, 81, 46-48.

Vogelzang, J., Admiraal, W. F., \& Van Driel, J. H. (2020a). A teacher perspective on Scrum methodology in secondary chemistry education. Chemistry Education Research and Practice, 21, 237-249.

Vogelzang, J., Admiraal, W. F., \& Van Driel, J. H. (2020b). Effects of Scrum methodology on students' critical scientific literacy: The case of Green Chemistry. Chemistry Education Research and Practice, 21, 940-952.

Yakovyshyna, T. (2018). AGILE-methodology as a factor in the modernization of modern educational space. Current Issues of Humanities, 19(2), 217223. 